\title{
Macrophage Migration Inhibitory Factor in the Early Diagnosis of Endometriosis and Relationship to the Stage of the Disease
}

\author{
Abdel Monem M. Zakaria ${ }^{(1)}$, Sameh S. Sayed ${ }^{(1)}$, Mekky A. Aly ${ }^{(2)}$, Wael M. Abou Hedeba ${ }^{(1)}$ \\ (1) Department of Obstetrics and Gynecology, ${ }^{(2)}$ Department of Clinical Pathology \\ Faculty of Medicine - Al Azhar University \\ Corresponding author: Wael M. Abou Hedeba, Mobile: 01062717150; Email: waelabohedeba@gmail.com
}

\begin{abstract}
Background: Endometriosis is a chronic disease affecting women of reproductive age. Adolescent onset of symptoms is common. Macrophage migration inhibitory factor (MIF) is one of non-invasive blood biomarker that was found in endometriosis. Aim of the work: to evaluate the value of macrophage MIF in peripheral blood of women with and without endometriosis as a non-invasive early diagnostic method and correlate its level to the stage of the disease. Patient and methods: This observational case-control study was conducted in El-Hussein Hospital, Al-Azhar University, Cairo and private clinics. The study was approved by the local research ethics committee. During the period from May 2016 till July 2018. Results: Both groups were comparable as regard the incidence of infertility and the presence of chronic pelvic pain. The infertility was equal in both groups; it affected 96\% of patients and control groups. The chronic pelvic pain was symmetrically present in both groups; it affected $70 \%$ of endometriosis and the control group. The level of MIF was $10.03 \pm 1.78 \mathrm{pg} / \mathrm{ml}$ in patients with endometriosis and $4.82 \pm 1.78 \mathrm{pg} / \mathrm{ml}$ in control group with significant $\mathrm{P}$ value $(\mathrm{P}<0.001)$. In our study, the level of MIF differed according to the stage of endometriosis, in stage I, it was $8.6 \pm 0.2 \mathrm{pg} / \mathrm{ml}$, in stage II, it was $10.1 \pm 0.1 \mathrm{pg} / \mathrm{ml}$, in stage III, it was $11.3 \pm 0.2 \mathrm{pg} / \mathrm{ml}$ and in stage IV, it was $14 \pm 0.0 \mathrm{pg} / \mathrm{ml}$. Conclusion: MIF factor is a promising marker not only for noninvasive diagnosis of endometriosis but as a target for therapy also.
\end{abstract}

Keywords: Macrophage Migration Inhibitory Factor, Endometriosis and Stage of the Disease.

\section{INTRODUCTION}

Endometriosis is a complex and mysterious disease. It is unknown why and when it begins, whether different disease types share a common origin and what caused the wide individual variation in pain symptoms, disease severity and tendency to progress. Even the nature of endometriosis as being a chronic and progressive disease is being debated ${ }^{(\mathbf{1})}$.

Endometriosis is defined histologically by the presence of endometrium glands and stroma outside the uterine cavity. By time, it forms a cyst that can vary in size from a few millimeters to over $20 \mathrm{~cm}$, and it contains old blood, giving it the nickname "chocolate cyst" (2). Clinically it forms macroscopically detectable lesions of three types: peritoneal i.e. superficial lesions, ovarian endometriotic cysts i.e. endometrioma (OMA) and deep lesions i.e. deep infiltrating endometriosis (DIE) (3).The prevalence of endometriosis among the general female population is unknown because presently the only reliable method to confirm the diagnosis is laparoscopy ${ }^{(4)}$.

It is well documented that there is a long diagnostic delay worldwide between the onset of symptoms and the diagnosis ${ }^{(5,6)}$.

A Cochrane Review of blood biomarkers for endometriosis included 141 studies that evaluated 122 biomarkers. These included angiogenesis factors, growth factors, apoptosis markers, cell adhesion molecules, high-throughput markers (biomarkers searched from the proteome of metabolome), hormones, immune system or inflammatory markers, oxidative stress markers, microRNAs (miRNA), tumor markers and other proteins ${ }^{(7)}$.

Macrophage migration inhibitory factor (MIF) is one of non-invasive blood biomarker that was found in endometriosis. MIF might have a great relationship with the neovascularization of ectopic endometrial implants. In 2005, Cao et al. using ELISA to measure peripheral blood MIF of women suffering from endometriosis, the result showed that the level of MIF in peripheral blood of women with endometriosis increased by $364 \%$ than normal controls. It rose significantly in the earlier stage and reached its peak level in the advanced stages (III-IV); those findings elucidated a plausible link between MIF and the disease progress. On the other hand, MIF can also stimulate endometriotic stromal cells to produce potent angiogenic factors ${ }^{(\mathbf{8})}$.

\section{AIM OF THE WORK}

The aim of this study is to evaluate the value of macrophage migration inhibitory factor in peripheral blood of women with and without endometriosis as a non-invasive early diagnostic method and correlate its level to the stage of the disease.

\section{PATIENT AND METHODS}

This study was an observational study of casecontrol type performed in El-Hussein hospital, AlAzhar University, Cairo and private clinics. The study was approved by the local research ethics committee. During the period between May 2016 and July 2018, 100 patients candidate for diagnostic laparoscopy were included. 
Macrophage Migration Inhibitory Factor...

Inclusion criteria:

1. Patients in childbearing period

2. History suggestive of endometriosis i.e. chronic pelvic pain (CPP), dysmenorrhea either primary or secondary....etc.

3. Fit for general anesthesia and laparoscopy.

4. No hormonal therapy for the last 3 months.

\section{Exclusion criteria:}

1. Ladies with other causes of CPP.

2. Unfit for general anesthesia

3. Unfit for laparoscopy

4. Patients with bleeding tendency

5. Suspicious of gynecologic malignancy

6. Suspicious of infection. It may give false

high MIF.

Each patient was subjected to:

- Informed consent: we discussed with every patient the simplicity of study design, advantages and disadvantages of being included in our study and the scientific value of our research. The accepting ones had signed a consent form.

- Full medical history: personal, present, family and past history

- Thorough Clinical examination with special attention to medical fitness for general anesthesia.

\section{Preoperative assessment}

A routine detailed medical history taking, physical and gynecological examinations were done.

\section{Investigations:}

1) Laboratory investigation:

a) $\mathrm{CBC}$, iron, and ferritin were recorded.

b) Coagulation profile.

c) Thyroid function tests

d) Liver, and kidney function tests

e) Vaginal and urine cultures

2) Histopathological investigations:

Cervico-vaginal smear were performed; Papanicolaou smear (For exclusion of cervical atypia).

3) Radiological assessment

All patients had evaluation by transvaginal ultrasonography (TVU) for:

a) Assessment of uterine size

b) Exclude fibroids

c) Any adnexial pathology

d) Assessment of uterine cavity, endometrial thickness.

e) Search for endometriosis, site, size and surrounding.

\section{Collection of blood sample for MIF:}

Five milliliters was collected from the vein in antecubital fossa on the morning following admission or in outpatient clinic visit prior to admission for seventy patients.
The samples were centrifuged at $3500 \mathrm{r} / \mathrm{min}$ for 10 minutes to separate the serum then stored $-20^{\circ} \mathrm{C}$ for further assessment.

MIF was measured by ELISA technique.

\section{Intraoperative assessment}

In fifty cases of study group, we took a laparoscopic biopsy from suspected lesions that were diagnosed histopathologically as endometriosis.

In control group, the patients didn't have endometriosis.

Assessment of the degree of endometriosis:

- The four stages of endometriosis are evaluated using the following criteria: endometrial implants, location, extent, depth, endometriomas, presence, size, adhesions and severity.

- Stage I: Superficial implants

- Stage II: Black spots appear over the fibrous adhesions which have grown in intensity

- Stage III: Chocolate cysts get their name because after time, the blood inside of the cyst turns dark red and brown.

- Stage IV: Large number of cysts and severe adhesions. Endometriomas can grow very large - even as big as a grapefruit - during this stage.

\section{Postoperative care:}

All cases were admitted to the recovery room for 6 hours after the laparoscopy.

During their stay in the recovery room, they were assessed by the anesthetist as regard vital signs, conscious level and presence or absence of pain.

After six hours they were referred to general ward and finally discharged.

\section{Follow up plan:}

Every patient received a card for follow up in outpatient clinic firstly after one week then every month for three months and finally every year or when indicated.

Patients with infertility were referred to fertility unit for further assessment.

\section{Statistical analysis}

Data were analyzed using Statistical Program for Social Science (SPSS) version 20.0. Quantitative data were expressed as mean \pm standard deviation (SD). Qualitative data were expressed as frequency and percentage.

\section{The following tests were done:}

- Independent-samples t-test of significance was used when comparing between two means.

- A one-way analysis of variance (ANOVA) when comparing between more than two means. 
- Post Hoc test: Least Significant Difference (LSD) was used for multiple comparisons between different variables.

- Chi-square $\left(\mathrm{X}^{2}\right)$ test of significance was used in order to compare proportions between two qualitative parameters.

- Receiver operating characteristic (ROC curve) analysis was used to find out the overall predictivity of parameter in and to find out the best cut-off value with detection of sensitivity, specificity, PPV, and NPV at this cut-off value.

- The confidence interval was set to $95 \%$ and the margin of error accepted was set to $5 \%$. So, P-value $<0.05$ was considered significant.

\section{RESULTS}

Table (1): Endometriosis distribution of the patients and control group.

\begin{tabular}{|l|c|c|}
\hline \multirow{2}{*}{ Groups } & \multicolumn{2}{|c|}{ Endometriosis } \\
\cline { 2 - 3 } Patients & No. & \% \\
\hline II & 25 & $50.0 \%$ \\
\hline II & 7 & $14.0 \%$ \\
\hline III & 13 & $26.0 \%$ \\
\hline IV & 5 & $10.0 \%$ \\
\hline Control & & \\
\hline Polycystic ovaries & 10 & $20.0 \%$ \\
\hline Pelvic inflammatory disease & 10 & $20.0 \%$ \\
\hline Simple cyst & 10 & $20.0 \%$ \\
\hline Adhesions & 10 & $20.0 \%$ \\
\hline Free & 10 & $20.0 \%$ \\
\hline
\end{tabular}

This table shows that the endometriosis stage I (50\%), Stage II (14\%), Stage II (26\%) and Stage IV (10\%) of patients study, while PCO (20\%), PID (20\%), simple cyst (20\%), adhesions (20\%) and free (20\%) of control.

Table (2): Comparison between patients and control according to type of fertile.

\begin{tabular}{|c|c|c|c|c|c|c|}
\hline \multirow{2}{*}{$\begin{array}{c}\text { Type of } \\
\text { Infertility }\end{array}$} & \multicolumn{2}{|c|}{ Patients } & \multicolumn{2}{c|}{ Control } & \multicolumn{2}{c|}{ Chi-square test } \\
\cline { 2 - 6 } & No. & $\mathbf{\%}$ & No. & $\mathbf{\%}$ & $\mathbf{x}^{\mathbf{2}}$ & p-value \\
\hline Primary & 33 & $68.8 \%$ & 23 & $47.9 \%$ & & \multirow{2}{*}{0.062} \\
\hline Secondary & 15 & $31.3 \%$ & 25 & $52.1 \%$ & & \\
\hline Total & 48 & $100.0 \%$ & 48 & $100.0 \%$ & & \\
\hline
\end{tabular}

This table shows no statistically significant difference between groups according to type of infertility.

Table (3): Comparison between patients and control according to fertility.

\begin{tabular}{|c|c|c|c|c|c|c|}
\hline \multirow{2}{*}{ Fertility } & \multicolumn{2}{|c|}{ Patients } & \multicolumn{2}{c|}{ Control } & \multicolumn{2}{c|}{ Chi-square test } \\
\cline { 2 - 6 } & No. & $\mathbf{\%}$ & No. & $\%$ & $\mathbf{x}^{\mathbf{2}}$ & p-value \\
\hline Fertile & 2 & $4.0 \%$ & 2 & $4.0 \%$ & 0 & 1 \\
\hline Infertile & 48 & $96.0 \%$ & 48 & $96.0 \%$ & & \\
\hline Total & 50 & $100.0 \%$ & 50 & $100.0 \%$ & & \\
\hline
\end{tabular}

This table shows no statistically significant difference between groups according to fertility.

Table (4): Comparison between patients and control according to pain.

\begin{tabular}{|c|c|c|c|c|c|c|}
\hline \multirow{2}{*}{ Pain } & \multicolumn{2}{|c|}{ Patients } & \multicolumn{2}{c|}{ Control } & \multicolumn{2}{c|}{ Chi-square test } \\
\cline { 2 - 6 } & No. & $\mathbf{\%}$ & No. & $\%$ & $\mathbf{x}^{\mathbf{2}}$ & p-value \\
\hline No Pain & 15 & $30.0 \%$ & 15 & $30.0 \%$ & \multirow{2}{*}{0} & \multirow{2}{*}{1.000} \\
\hline Pain & 35 & $70.0 \%$ & 35 & $70.0 \%$ & \\
\hline Total & 50 & $100.0 \%$ & 50 & $100.0 \%$ & & \\
\hline
\end{tabular}

This table shows no statistically significant difference between groups according to pain.

Table (5): Comparison between patients and control according to MIF (pg/ml).

\begin{tabular}{|c|c|c|c|}
\hline MIF (pg/ml) & Control & Patients & p-value \\
\hline Mean \pm SD & $4.82 \pm 1.78$ & $10.03 \pm 1.78$ & \multirow{2}{*}{$<0.001$} \\
\hline Range & $2.4-7.5$ & $8.2-14$ & \\
\hline
\end{tabular}

This table shows highly statistically significant difference between groups according to MIF (pg/ml). 
Macrophage Migration Inhibitory Factor...

Table (6): Comparison between control and endometriosis stage according to MIF (pg/ml).

\begin{tabular}{|c|l|l|l|l|l|l|}
\hline \multirow{2}{*}{ MIF (pg/ml) } & \multirow{2}{*}{ Control } & \multicolumn{4}{|c|}{ Endometriosis Stage } & \multirow{2}{*}{ Stage I } \\
\cline { 3 - 6 } & & Stage II & Stage III & $\begin{array}{c}\text { Stage } \\
\text { IV }\end{array}$ & \\
\hline Mean \pm SD & $4.8 \pm 1.8$ & $8.6 \pm 0.2$ & $10.1 \pm 0.1$ & $11.3 \pm 0.2$ & $14 \pm 0.0$ & \\
\hline Range & $2.4-7.5$ & $8.2-8.8$ & $10-10.1$ & $11.1-11.6$ & $14-14$ & \\
\hline$\# I$ & & $<0.001$ & $<0.001$ & $<0.001$ & $<0.001$ & \multirow{2}{*}{$<0.001$} \\
\hline$\# I I$ & & & $<0.001$ & $<0.001$ & $<0.001$ & \\
\hline$\# I I$ & & & & 0.009 & $<0.001$ & \\
\hline$\# I V$ & & & & & $<0.001$ & \\
\hline
\end{tabular}

\#I Comparison between Control and endometriosis stages

\#II Comparison between Stage I and Other stages

\#III Comparison between Stage II and Other stages

\#IV Comparison between Stage III and IV stage

This table shows highly statistically significant difference between control and endometriosis stages according to MIF $(\mathrm{pg} / \mathrm{ml})$.

Table (7): Comparison between control and fertile according to MIF (pg/ml).

\begin{tabular}{|c|c|c|c|c|}
\hline MIF (pg/ml) & Control & Fertile & Infertile & p-value \\
\hline Mean \pm SD & $4.82 \pm 1.78$ & $11.60 \pm 0.00$ & $9.96 \pm 1.79$ & \\
\cline { 1 - 4 } Range & $2.4-7.5$ & $11.6-11.6$ & $8.2-14$ & \multirow{2}{*}{$<0.001$} \\
\cline { 1 - 3 }$\#$ \#II & & $<0.001$ & $<0.001$ & \\
\hline
\end{tabular}

This table shows highly statistically significant difference between control and fertile according to MIF (pg/ml).

Table (8): Comparison between control and type of fertility according to MIF (pg/ml).

\begin{tabular}{|c|c|c|c|c|}
\hline MIF (pg/ml) & Control & Primary & Secondary & p-value \\
\cline { 1 - 4 } Mean \pm SD & $4.74 \pm 1.79$ & $10.12 \pm 2.05$ & $9.61 \pm 0.94$ & \\
\cline { 1 - 3 }$<0.001$ & $8.2-14$ & $8.5-11.1$ & \\
\cline { 1 - 3 } Range & $2.4-7.5$ & $<0.001$ & 0.001 & \\
\cline { 1 - 2 } & & & 0.356 & \\
\hline
\end{tabular}

This table shows highly statistically significant difference between control and type of fertility according to MIF (pg/ml).

Table (9): Comparison between control and pain according to MIF (pg/ml).

\begin{tabular}{|c|c|c|c|c|}
\hline MIF (pg/ml) & Control & No Pain & Pain & p-value \\
\hline Mean \pm SD & $4.82 \pm 1.78$ & $8.73 \pm 0.59$ & $10.58 \pm 1.83$ & \\
\cline { 1 - 4 } Range & $2.4-7.5$ & $8.2-10.1$ & $8.5-14$ & \\
\cline { 1 - 3 } & & $<0.001$ & $<0.001$ & \\
\cline { 1 - 3 }$\#$ \#II & & & $<0.001$ & \\
\hline
\end{tabular}

This table shows highly statistically significant difference between control and pain according to MIF (pg/ml).

Table (10): Diagnostic Performance of MIF in Discrimination of patients and control

\begin{tabular}{|c|c|c|c|c|c|}
\hline Cut-off & Sen. & Spe. & PPV & NPV & Accuracy \\
\hline$>7.5$ & $100 \%$ & $100 \%$ & $100 \%$ & $100 \%$ & $100 \%$ \\
\hline
\end{tabular}

Receiver operating characteristics (ROC) curve was used to define the best cut off value of MIF which was $>7.5$, with sensitivity of $100 \%$ specificity of $100 \%$ positive predictive value of $100 \%$, negative predictive value of $100 \%$ with diagnostic accuracy of $100 \%$.

\section{DISCUSSION}

Endometriosis is a chronic disease affecting women of reproductive age. Typical symptoms include severe menstrual pain, other pelvic pain symptoms as well as infertility. Adolescent onset of symptoms is common also ${ }^{\left({ }^{(9)}\right.}$. The only reliable and considered as gold standard method to confirm the diagnosis is laparoscopy ${ }^{(7)}$.
Macrophage migration inhibitory factor (MIF) is one of non-invasive blood biomarker that was found in endometriosis. Therefore, world health organization (WHO), obstetrics and gynecological scientists and other organizations that care about women's health paid great attention to create new non-traditional (non-surgical) methods to predict 
and early diagnose endometriosis as it affects a nonnegligible section of women ${ }^{(9)}$.

This study is a case-control observational study to assess the diagnostic value of macrophage migration inhibitory factor (MIF) in endometriosis.

All selected cases were investigated by MIF; one hundred cases were enrolled from whom fifty cases were proved to be endometriosis, and fifty cases were free of endometriosis from whom ten were diagnosed as polycystic ovarian syndrome, ten were pelvic inflammatory disease, ten with simple cyst, ten with adhesions and ten were free by laparoscopy.

Our design was to compare the level of MIF in patients with endometriosis with its level in patients suffers from other gynecological diseased necessitate laparoscopy, while most studies assessed the diagnostic performance combined tests of 3-6 biomarkers. The majority of studied biomarkers did not differentiate endometriosis patients from healthy controls ${ }^{(9)}$.

Both groups were comparable as regard the incidence of infertility and the presence of chronic pelvic pain. The infertility was equal in both groups; it affected $96 \%$ of patients and control groups. The chronic pelvic pain was symmetrically present in both groups; it affects $70 \%$ of endometriosis and the control group.

The level of MIF was $10.03 \pm 1.78 \mathrm{pg} / \mathrm{ml}$ in patients with endometriosis and $4.82 \pm 1.78 \mathrm{pg} / \mathrm{ml}$ in control group with significant $\mathrm{P}$ value $(\mathrm{P}=<0.001)$.

In our study, the level of macrophage migration inhibitory factor (MIF) differed according to the stage of endometriosis, in stage I, it was $8.6 \pm 0.2 \mathrm{pg} / \mathrm{ml}$, in stage II, it was $10.1 \pm 0.1 \mathrm{pg} / \mathrm{ml}$, in stage III, it was $11.3 \pm 0.2 \mathrm{pg} / \mathrm{ml}$ and in stage IV, it was $14 \pm 0.0 \mathrm{pg} / \mathrm{ml}$. All these figures are lower than Nisenblat and coworkers, who diagnosed endometriosis above $0.57 \mathrm{ng} / \mathrm{ml}{ }^{(7)}$.

Zhang and Mu measured serum MIF in endometriosis stage I, $1.14 \pm 0.21$ and stage II = $1.76 \pm 0.27$ and stage $\mathrm{III}=2.28 \pm 0.42$ and stage $\mathrm{IV}=2.64 \pm 0.53$ microgram $/ \mathrm{L} \quad(1$ microgram is 1000000 picogram and 1 liter is $1000 \mathrm{ml}$ so, the results of our study are much lower than Zhang's; this is because of different kits and method ${ }^{(11)}$.

The value of our results could not be compared to others because we used different techniques and kits. We used statistically significance instead.

The level of MIF cannot predict the type of infertility either primary or secondary or presence or absence of pain.
We need a meta-analysis to be performed on antiendometrial antibodies, interleukin-6 (IL-6), cancer antigen 19-9 (CA-19-9) and CA-125. The majority of studied biomarkers did not differentiate endometriosis patients from healthy controls ${ }^{(9)}$.

\section{CONCLUSION}

Macrophage migratory inhibitory factor is a promising marker not only for noninvasive diagnosis of endometriosis but as a target for therapy also.

\section{REFERENCES}

1. Canis M, Bourdel N, Houlle C et al. (2016). Endometriosis may not be a chronic disease: an alternative theory of- fering more optimistic prospects for our patients. Fertil Steril, 105: 32-4.

2. Giudice LC (2010): Endometriosis. N Engl J Med., 362: 2389-98.

3. Scioscia M, Bruni F, Ceccaroni $M$ et al. (2011): Distribution of endometri- otic lesions in endometriosis stage IV sup- ports the menstrual reflux theory and requires specific preoperative assessment and therapy. Acta Obstet Gynecol Scand., 90: 136-9.

4. Hickey M, Ballard $K$ and Farquhar $C$ (2014): Endometriosis. BMJ., 348, g1752.

5. Nnoaham KE, Hummelshoj L, Webster P et al. (2011): Impact of endometriosis on quality of life and work productivity: a multicenter study across ten countries. Fertil Steril., 96, 366-373.e8.

6. Dunselman GA, Vermeulen N, Becker $C$ et al. (2014): ESHRE guide- line: management of women with endometriosis. Hum Reprod., 29, 400-12.

7. Nisenblat V, Bossuyt R, Shaikh FC et al. (2016): Blood biomarkers for the non- invasive diagnosis of endometriosis. doi: 10.1002/14651858.CD012179.

8. Cao WG, Morin M, Metz C et al. (2005): Stimulation of macrophage migration inhibitory factor expression in endometrial stromal cells by interleukin, beta involving the nuclear transcription factor NFkappaB. Biol Reprod., 73: 565-570.

9. Suvitie P (2018): Modern methods of Evaluating endometriosis. Publications of the University of Turku Annales Universitatis Turkuensis https://www.utu.fi/en/units/library/requestbuypublish/publi sh/publishing-doctoral-dissertation/annalesserial/Pages/home.aspx

10. Evers J (2013): Is adolescent endometriosis a progressive disease that needs to be diagnosed and treated? Human Reproduction, 28: 2023-2029.

11. Zhang $X$, Mu $L$ (2015): Association between macrophage migration inhibitory factor in the endometrium and estrogen in endometriosis. Experimental and Therapeutic Medicine, 10(2):787-91. 